\title{
NEUROENDOCRINE DISTURBANCES FOLLOWING HEAD INJURIES
}

\author{
Vinayak Raje1, Sangeeta Biradar², Mahesh Reddy³, Madhavendra Kabra, Shruthi Panicker ${ }^{5}$
}

\section{HOW TO CITE THIS ARTICLE:}

Vinayak Raje, Sangeeta Biradar, Mahesh Reddy, Madhavendra Kabra, Shruthi Panicker. "Neuroendocrine Disturbances Following Head Injuries". Journal of Evolution of Medical and Dental Sciences 2015; Vol. 4, Issue 43, May 28; Page: 7567-7575, DOI: 10.14260/jemds/2015/1099

ABSTRACT: INTRODUCTION: Traumatic brain injury (TBI) is one of the main causes of death and disability in young adults, with consequences ranging from physical disabilities to long-term cognitive, behavioural, psychological and social defects. Recently, clinical evidence has demonstrated that TBI may frequently cause hypothalamic-pituitary dysfunction, probably contributing to a delayed or hampered recovery from TBI. CASE REPORT: 32 years old female presented with a history of fall from two wheeler on back hitting the head on occipital region with no history of vomiting, loss of consciousness, ENT bleed. Her GCS was 15/15. Patient was asymptomatic and was discharged from hospital on fifth day. Seven days after discharge patient again presented with heaviness in her both breasts associated with pain and whitish discharge from both the nipples and mild fever since last two days. CONCLUSION: TBI is a public health problem that requires more effective strategies to improve the outcome and minimize disability of the affected patients. Changes in pituitary hormone secretion may be observed during the acute phase post-TBI, representing part of the acute adaptive response to the injury. Neuroendocrine disturbances, caused by damage to the pituitary and/or hypothalamus, is a frequent complication of TBI and may occur at any time after the acute event. Pituitary dysfunction presents more frequently as an isolated, and more rarely as a complete, deficiency.

KEYWORDS: Neuroendocrine disturbances, Hypopituitarism, Hypothalamus, Traumatic brain injury, diabetes insipidus.

INTRODUCTION: Traumatic brain injury (TBI) is one of the main causes of death and disability in young adults, with consequences ranging from physical disabilities to long-term cognitive, behavioural, psychological and social defects; ${ }^{(1,2)}$ these long-term consequences make TBI a public health problem.(3)

Post-traumatic hypopituitarism (PTHP) was recognized more than 80 years ago,(4) but it was thought to be a rare occurrence. Recently, TBI has been demonstrated to be a frequent cause of hypothalamic-pituitary dysfunction, contributing to a delayed or hampered recovery. $(5,6,7,8,9,10)$

The anatomic and physiologic complexities of the hypothalamus and pituitary gland increase their susceptibility to injury from TBI. The pituitary gland is connected to the hypothalamus by a stalk containing blood vessels, making the pituitary gland-particularly the anterior portionsusceptible to damage during a head injury.(11) Anterior pituitary hormones are growth hormone $(\mathrm{GH})$, luteinizing hormone (LH), follicle-stimulating hormone (FSH), adrenocorticotropic hormone (ACTH), thyroid-stimulating hormone (TSH), and prolactin (PRL). The posterior pituitary secretes oxytocin and vasopressin also known as antidiuretic hormone (ADH).

Impact from a direct blow with an object or from a concussive blast can cause focal trauma or rotational shearing of tissue internally. Resultant vascular injury, rupture, cerebral edema, vasospasm, pituitary swelling, or inflammation may then initiate an endocrine response that drives a cascade of complex hormonal processes.(12,13,14) 
Anterior pituitary deficiencies account for the majority of chronic neuroendocrine disorders following TBI. GH and gonadotropin deficiencies are the most common, but TSH deficiency (Secondary hypothyroidism) and ACTH deficiency (Adrenal insufficiency) may occur as well, although in $<10 \%$ of cases with TBI associated NED.(15) The prevalence of any anterior pituitary hormone deficiency is as high as $30 \%$ to hormone deficiency is as high as $30 \%$ to $80 \%$ at 24 to 36 months post injury.

The prevalence of posterior pituitary hormone deficiency is as high as $4 \%$ to $7 \%$ at 12 months post injury. The anterior pituitary hormones most frequently affected in survivors of TBI are ACTH, gonadotropin, prolactin, and GH. In 2004 Agha et al,(16) reported $>28 \%$ of survivors of TBI had at least one anterior pituitary hormone deficiency. According to research by Agha et al(17) in 2005, $>20 \%$ of survivors of TBI developed DI; those who developed DI, either acutely or permanently, were more likely to have sustained a severe TBI. The development of pituitary dysfunction is independent of the severity of TBI. In 2005, civilian guidelines 4 recommended screening for pituitary dysfunction in all patients who sustained a moderate to severe TBI. In 2010, civilian guidelines 7 recommended screening for pituitary dysfunction in patients who sustained mild TBI.

CASE REPORT: A32 years old female presented with a history of fall from two wheeler on back, hitting the head on occipital region, with immediate no history of vomiting or loss of consciousness or ENT bleed, with a GCS of 15/15. Patient discharged from hospital on fifth day. Seventh day after discharge patient again presented with heaviness in both breasts associated with pain and whitish discharge from both the nipples and mild fever since last two days.

On examination patient was conscious, oriented, and afebrile with GCS of 15/15, pupils were normal in size and bilaterally reacting to light. All the routine investigations of the patient at the time of admission were normal, with normal CT scan findings. So patient was discharged from the hospital on fifth day. Her hospital stay was uneventful. On seventh day after discharge, patient came for follow up with complaints of fullness of both the breasts associated with pain and whitish discharge from both the nipples and mild fever since last two days. On screening her prolactin levels were within the normal limits of 4.4. (Normal 2.5-30).

DISCUSSION: TBI is a non-degenerative, non-congenital insult to the brain from an external mechanical force causing temporary or permanent neurological dysfunction, which may result in impairment of cognitive, physical and psychosocial functions. The overall incidence of TBI in developed countries is about 200/100 000 population per year.(18) The highest incidence of TBI is among subjects aged 15-24 years or 75 years and older, with an additional incidence peak in children aged 5 years and younger.(3,18) Incidence rate for males is almost twice that for females, with the highest male: female (M:F) ratio occurring in adolescence and young adulthood, and ranging from 1.2:1 to $4.4: 1$ in different populations.(19,20,21,22,23,24,25) $\mathrm{M}$ : $\mathrm{F}$ ratio approaches parity with ageing owing to the increased likelihood of TBI caused by falls, for which members of both sexes have similar risks in later life.(18)

Approximately $50 \%$ of TBIs are the result of motor vehicle, bicycle or pedestrian-vehicle accidents. Falls are the second-commonest cause of TBI (20-30\% of all TBI), being more frequent among the elderly and the very young population. Violence-related incidents account for approximately $20 \%$ of TBI, almost equally divided into firearm and non-firearm assaults.(3) 
Several classifications for TBI severity are reported in the literature. The post-resuscitation Glasgow Coma Scale is the most widely used clinical classification of TBI severity. GCS is based on the patient's response (Eye opening, verbal and motor function) to various stimuli.

A score of 13-15 is considered mild, 9-12 moderate and $\leq 8$ severe TBI.(26) Clinical severity of TBI is also defined by duration of loss of consciousness (LOC), loss of memory for events immediately before or after the accident (Post-traumatic amnesia) and identified intracranial lesion.(18,27) Radiological findings by computed tomography (CT) may be helpful in TBI severity evaluation, and the most used radiological scale is the Marshall's classification.(28) Functional outcome after TBI is usually evaluated by the Glasgow Outcome Scale (GOS), a descriptive and easy to use scale, describing five outcome categories(death, vegetative, severely disabled, moderately disabled, good recovery).(29)

\section{NEUROENDOCRINE DISTURBANCES INCLUDE:}

GH/IGF-1 deficiency: $\left(\mathbf{1 0 \%}^{\mathbf{3 0}-29 \%} \mathbf{0}^{\mathbf{1 3}}\right)$ : Increased fatigue, decreased concentration, memory impairment, impaired judgment and problem-solving, anxiety, depression.

Poor quality of life, decreased lean body mass, impaired cardiac function, dyslipidemia, reduced bone mineral density, decreased vigor, hypertension, insulin resistance, enhance thrombotic factors, abdominal fat mass.

GONADOTROPIN (LH /FSH) DEFICIENCY: $\left(2 \%{ }^{30}\right.$ - 16.8\% $\left.{ }^{15}\right)$ :

Women: Oligomenorrhea/amenorrhea, sexual dysfunction, breast atrophy.

Men: Infertility, decreased libido, erectile dysfunction, testisatrophy, decreased muscle mass, decreased exercise tolerance, anemia.

Both: Decreased pubic and axillary hair, increased perioral and periocular skin wrinkles, mood disorders, decreased vigour, reduced bone mineral density, poor quality of life.

CORTICOSTEROID (ACTH) DEFICIENCY: (5\%30 - 9.6\%13): Decreased energy, malaise, depression, fatigue, anxiety Life-threatening adrenal crisis (shock, weakness, nausea, vomiting, fever, poorly localized abdominal/flank pain, weakness, confusion), hypoglycemia, hyponatremia, myopathy, anemia, apathy, weight loss, loss of libido.

TSH DEFICIENCY: (3\% $\left.\mathbf{3}^{\mathbf{1 3}}\right)$ : Decreased energy, depressed mood, fatigue, poor memory, cognitive impairment cold intolerance, weight gain, muscle cramps, constipation, myopathy, hypotension, bradycardia, neuropathy, skin, hair and voice changes, somnolence.

\section{HYPERPROLACTINEMIA OR HYPOPROLACTINEMIA: $\left(8 \%{ }^{31}\right)$ :}

\section{Sudden onset Depression:}

Women: Amenorrhea, oligomenorrhea, galactorrhea, infertility, hot flashes, vaginal dryness, hirsuitism in postmenopausal women.

Men: Decreased libido, impotence.

ADH INSUFFICIENCY: (Diabetes insipidus) (2\% dehydration, excessive thirst, hyponatremia (weakness, altered mental status, coma, seizures).

MULTIPLE HORMONAL DYSFUNCTION: (3.2\%13-5\% $\left.{ }^{33}\right):$ ACTH, adrenocorticotropic hormone; $\mathrm{ADH}$, antidiuretic hormone; FSH, follicle-stimulating hormone; $\mathrm{GH}$, growth hormone;

IGF-1, insulin-like growth factor 1; LH, luteinizing hormone; mTBI, mild traumatic brain injury; PRL, prolactin; TSH (Thyroid stimulating hormone). 
Pituitary dysfunction following traumatic events can be divided into: (a) functional alterations during the acute phase post-TBI, which result in a temporary increase or decrease in blood pituitary hormone concentrations; (b) alterations in pituitary hormone secretion that may occur at any time after TBI, resulting in permanent hypopituitarism caused by damage at pituitary and/or hypothalamic level.

SCREENING FOR NEUROENDOCRINE DYSFUNCTION: Though NED has similarities with conditions like sleep disorder, memory difficulties, depression, PTSD and others, NED should be in the primary care setting following confirmed TBI of any severity level when symptoms suggestive of NED persist for $>3$ months following injury or appear up to 36 months later.(13,14,15,34)

Screen for NED with confirmed TBI of any severity level if suggestive symptoms persist for $>3$ months or appear up to 36 months following injury. Order a lab evaluation of blood levels for cortisol (Drawn at $8 \mathrm{am}$ ), LH, FSH, PRL, insulin-like growth factor-1, TSH, free thyroxine-4, and testosterone for men ( $8 \mathrm{am})$ and estradiol for women (8 am). With frankly abnormal lab results or with borderline results and strong clinical suspicion for NED, refer for further endocrinology workup Figure. 21 Earlier diagnosis of NED results in more rapid improvement of symptoms and an improved prognosis.(13,14,34) Post injury screening for NED should be one component of a thorough clinical evaluation by a qualified provider, and not used in isolation for clinical decision making. NED screening should not be routinely ordered during the early stages of TBI, defined as $<3$ months post injury.

Provider awareness and willingness to include NED screening in a timely manner, and to refer to specialty services as indicated for symptoms that may be sleep related or psychiatric in nature, may increase the opportunities for early treatment, better rehabilitation outcomes, and better overall quality of life.

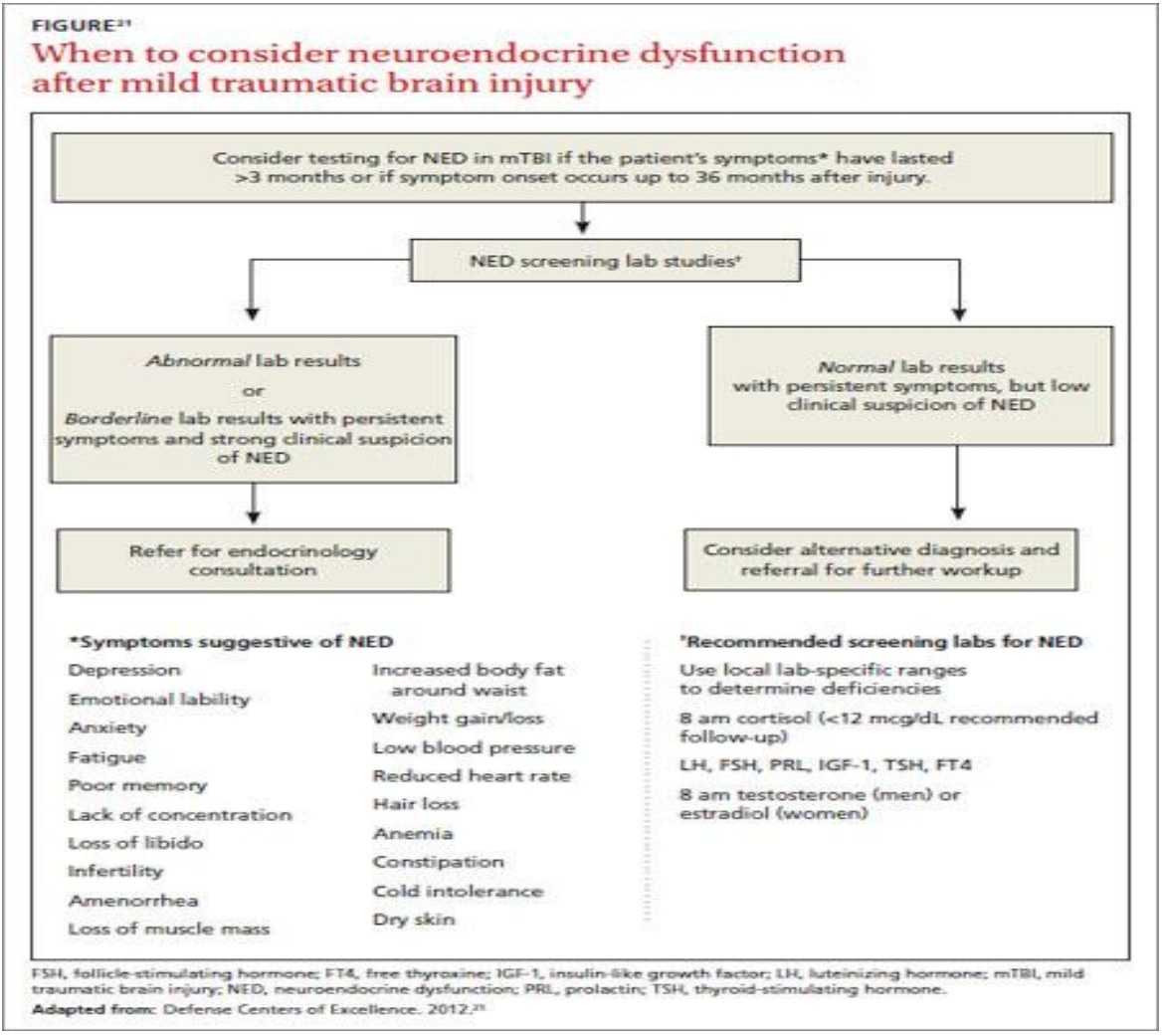


CONSEQUENCES: Pituitary insufficiency may have serious consequences, possibly aggravating the physical and neuropsychiatric morbidity observed after TBI:

1. Acute glucocorticoid deficiency can be life threatening, while mild chronic deficiency may impair recovery and rehabilitation after TBI since it causes fatigue, weakness and inability to respond to stress.

2. Hypothyroidism causes apathy, muscle weakness and cognitive dysfunction.

3. GHD is associated with reduced lean body mass, reduced bone mineral density, decreased exercise capacity, impaired cardiac function, social isolation and reduced psychophysical wellbeing, which may hamper recovery in TBI patients. Besides the effect on libido and fertility, estrogen deficiency in females promotes osteoporosis, and testosterone deficiency in males leads to reduced lean body mass and bone mineral density.(35,36)

4. Diabetes insipidus causes a volume-depleted state with subsequent hypernatremia that can predispose to seizures and to severe dehydration.(37)

PTHP may develop during the recovery phase, which lasts at least 2-5 years.(2,38) Therefore, an early diagnosis is crucial, since an adequate replacement therapy may result in an improvement in the outcome. As mentioned above, either positive or negative relationships between pituitary dysfunction and outcome from TBI have been observed in the early, acute phase post-TBI.(39,40,41,42) We did not find any statistical correlation between outcome measures and presence of pituitary dysfunction, both in patients examined over a 5-years period after TBI(5) and in patients evaluated during the early rehabilitation period.(43) Autopsy studies demonstrated a high incidence (14-74\%) of anatomical lesions in the hypothalamic-pituitary region; this suggests, therefore, that hypopituitarism might contribute to the poor prognosis of the TBI patients. $(44,45,46,47)$

All patients hospitalized for TBI should undergo an adequate evaluation of anterior and posterior pituitary function. Patients with severe injury or basilar skull fractures are at major risk for developing PTHP and/or posterior pituitary dysfunction. Assessment of fluid and electrolyte balance is useful for the diagnosis of diabetes insipidus or SIADH, in order to correct these syndromes and avoid their complications.

PTHP should be considered in TBI patients with unexplained symptoms (Hypotension, weight loss, fatigue, loss of libido, depression) or suspicious biochemical alterations (Hyponatremia, hypoglycemia, reduced blood cell count, etc.), and in those who do not achieve the expected recovery. Despite the challenges of diagnosis of corticotropin deficiency in the acute phase of critical illness, patients with suspected glucocorticoid deficiency require prompt and adequate replacement therapy.

Then, hypothyroidism should be treated. On the other hand, no consensus exists about the treatment of hypogonadism and GHD in the acute phase post-TBI. Recent studies have investigated the us of recombinant human GH (rhGH) and IGF-I (rhIGF-I) to reduce protein loss in catabolic states,(48-50) which resemble the acute phase of TBI. In patients undergoing major abdominal surgery, rhGH treatment has preserved limb lean tissue mass, increased postoperative muscular strength and reduced long-term postoperative fatigue.(51) It has been demonstrated that, in patients with HIVassociated wasting syndrome, high-dose rhGH treatment increases body weight, lean body mass and treadmill work output.(49,50) A multicenter trial has shown an association between rhGH treatment and increased mortality in intensive care unit patients, ${ }^{(52)}$ thus discouraging the application of such therapy in acute TBI. 
A long-term follow-up of these patients, as well as an evaluation of those with a previous history of TBI who escaped initial assessment, are then necessary to avoid the possibility that PTHP remains undiagnosed for months or years, hampering recovery and rehabilitation. The International Consensus Conference on rhGH replacement therapy,(53) suggests that severe GHD should be treated. GH replacement in GHD has largely been demonstrated to increase muscle mass, reduce body fat and have positive effects on cardiac profiles, exercise capacity, mood and quality of life; all of which may have a positive influence on recovery from TBI.(36,54) In this respect, growing evidence indicates that GH plays an important role in promoting recovery after experimental brain injury,(55,56) offering a possible additive advantage for TBI patients with GHD receiving GH replacement.

\section{REFERENCES:}

1. Salazar AM, Warden DL, Schwab K, Spector J, Braverman S, Walter J, Cole R, Rosner MM, Martin EM, Ecklund J \& Ellenbogen RG. Cognitive rehabilitation for traumatic brain injury: a randomized trial. Defense and Veterans Head Injury Program (DVHIP) Study Group. Journal of the American Medical Association 2000283 3075-3081.

2. Khan F, Baguley IJ \& Cameron ID. Rehabilitation after traumatic brain injury. Medical Journal of Australia 2003178 290-295.

3. Consensus Conference. Rehabilitation of persons with traumatic brain injury. NIH Consensus Development Panel on Rehabilitation of Persons with Traumatic Brain Injury. Journal of the American Medical Association1999 282 974-983.

4. Cyran E. Hypophysens chadigungdurch Schadel basis fraktur. Deutsche Medizinische Wochenschrift 1918441261.

5. Bondanelli M, de Marinis L, Ambrosio MR, Monesi M, Valle D, Zatelli MC, Fusco A, Bianchi A, Farneti M \& degli Uberti EC. Occurrence of pituitary dysfunction following traumatic brain injury. Journal of Neurotrauma2004 21 685-696.

6. Aimaretti G, Ambrosio MR, Di Somma C, Fusco A, Cannavò S, Gasperi M, Scaroni C, De Marinis L, Benvenga S, degli Uberti EC, Lombardi G, Mantero F, Martino E, Giordano G \& Ghigo E. Traumatic brain injury and subarachnoid haemorrage are conditions at high risk for hypopituitarism: screening study at 3 months after brain injury. Clinical Endocrinology $200461320-326$.

7. Lieberman SA, Oberoi AL, Gilkinson CR, Masel BE \& Urban RJ. Prevalence of neuroendocrine dysfunction in patients recovering from traumatic brain injury. Journal of Clinical Endocrinology and Metabolism 200186 2752-2756.

8. Masel BE. Rehabilitation and hypopituitarism after traumatic brain injury. Growth Hormone and IGF Research 2004; 14: (Suppl A) S108-S113.

9. Agha A, Rogers B, Sherlock M, O’Kelly P, Tormey W, Phillips J \& Thompson CJ. Anterior pituitary dysfunction in survivors of traumatic brain injury. Journal of Clinical Endocrinology and Metabolism 2004 894929-4936.

10. Elovic EP. Anterior pituitary dysfunction after traumatic brain injury. Part I. Journal of Head Trauma Rehabilitation 200318 541-543.

11. Amar AP, Weiss MH. Pituitary anatomy and physiology. Neurosurg Clin N Am. 2003; 14: 11-23.

12. Krahulik D, Zapletalova J, Frysak Z, et al. Dysfunction of hypothalamic-hyperphysical axis after traumatic brain injury in adults. J. Neurosurg. 2010; 113: 581-584. 
13. Tanriverdi F, Unluhizarci K, Kelestimur F. Pituitary function in subjects with mild traumatic brain injury: a review of literature and proposal of a screening strategy. Pituitary. 2010; 13: 146-153.

14. Bondanelli M, Ambrosio MR, Zatelli MC, et al. Hypopituitarism after traumatic brain injury. Eur J Endocrinol. 2005; 152: 679-691.

15. Schneider H, Kreitschman-Andermahr I, Ghigo E, et al. Hypothalamopituitary dysfunction following traumatic brain injury and aneurysmal subarachnoid hemorrhage: a systematic review. JAMA. 2007; 298: 1429-1438.

16. Agha A, Rogers B, Mylotte D, et al. Neuroendocrine dysfunction in the acute phase of traumatic brain injury. Clin Endocrinol (Oxf). 2004; 60: 584-591.

17. Agha A, Phillips J, O'Kelly $\mathrm{P}$, et al. The natural history of post-traumatic hypopituitarism: implications for assessment and treatment. Am J Med. 2005; 118: 1416.

18. Bruns JJr \& Hauser WA. The epidemiology of traumatic brain injury: a review. Epilepsia 2003; 44: (Suppl 10) 2-10.

19. Cooper KD, Tabbador K, Hauser WA, Shulman K, Feiner C \& Factor PR. The epidemiology of head injury in the Bronx. Neuroepidemiology 1983 270-88.

20. Durkin MS, Olsen S, Barlow B, Virella A \& Connolly ES Jr. The epidemiology of urban pediatric neurological trauma: evaluation of, and implications for injury prevention programs. Neurosurgery 199842 300-310.

21. Tiret L, Hausherr E, Thicoipe M, Garros B, Maurette P, Castel JP \& Hatton F. The epidemiology of head trauma in Aquitaine (France), 1986: a community-based study of hospital admissions and deaths. International Journal of Epidemiology 199019 133-140.

22. Andersson EH, Bjorklund R, Emanuelson I \& Stalhammar D. Epidemiology of traumatic brain injury: a population based study in western Sweden. Acta Neurologica Scandinavica 2003107 256-259.

23. Servadei F, Verlicchi A, Soldano F, Zanotti B \&Piffer S. Descriptive epidemiology of head injury in Romagna and Trentino. Comparison between two geographically different Italian regions. Neuroepidemiology2002 21 297-304.

24. Hillier SL, Hiller JE \& Metzer J. Epidemiology of traumatic brain injury in South Australia. Brain Injury 199711 649-659.

25. Nell V \& Brown DS. Epidemiology of traumatic brain injury in Johannesburg-II. Morbidity, mortality and etiology. Social Science and Medicine 199133 289-296.

26. Teasdale G \& Jennett B. Assessment of coma and impaired consciousness. A practical scale. Lancet 19742 81-84.

27. Greenwald BD, Burnett DM \& Miller MA. Congenital and acquired brain injury. 1. Brain injury: epidemiology and pathophysiology. Archives of Physical Medicine and Rehabilitation 200384 S3-S7.

28. Marshall LF, Marshall SB, Klauber MR, Van Berkum Clark M, Eisenberg H, Jane JA, Luerssen TG, Marmarou A \& Foulkes MA. The diagnosis of head injury requires a classification based on computed axial tomography. Journal of Neurotrauma 19929 S287-S292.

29. Jennett B \& Bond M. Assessment of outcome after severe brain damage. Lancet 19751480 484. 


\section{CASE REPORT}

30. Klose M, Watt T, Brennum J, et al. Posttraumatic hypopituitarism is associated with an unfavorable body composition and lipid profile, and decreased quality of life in 12 months after injury. J Clin Endocrinol Metab. 2007; 92: 3861-3868.

31. Bondanelli M, De Marinis L, Ambrosio MR, et al. Occurrence of pituitary dysfunction following traumatic brain injury. J Neurotrauma. 2004; 21: 685-696.

32. Aimeretti G, Ambrosio MR, Di Somma C, et al. Residual pituitary function after brain injuryinduced hypopituitaryism: a prospective 12-month study. J Clin Endocrinol Metab. 2005; 90: 6085-6092.

33. Tanriverdi F, Unluhizarci K, Kocyigit I, et al. Brief communication: Pituitary volume and function in competing and retired male boxers. Ann Intern Med. 2008; 148: 827-831.

34. Rothman MS, Arciniegas DS, Filley CM, et al. The neuroendocrine effects of traumatic brain injury.J Neuropsychiatry ClinNeurosci. 2007; 19: 363-372.

35. Lamberts SW, de Herder WW \& van der Lely AJ. Pituitary insufficiency. Lancet 1998352 127134.

36. Melmed S \& Kleinberg D. Anterior pituitary. In Williams Textbook of Endocrinology, edn 10, Ch 8, pp 177-279.Eds PR Larsen, HM Kronenberg, S Melmed \& KS Polonsky. Philadelphia, PA: Saunders, 2003.

37. Burnett DM, Watanabe TK \& Greenwald BD. Congenital and acquired brain injury. 2. Brain injury rehabilitation: medical management. Archives of Physical Medicine and Rehabilitation 200384 S8-S11.

38. Olver JH, Ponsford JL \& Curran CA. Outcome following traumatic brain injury: a comparison between 2 and 5 years after injury. Brain Injury 199610 841-848.

39. Hackl JM, Gottardis M, Wieser C, Rumpl E, Stadler C, Schwarz S \& Monkayo R. Endocrine abnormalities in severe traumatic brain injury. A cue to prognosis in severe craniocerebral trauma? Intensive Care Medicine1991 17 25-2

40. Gottardis M, Nigitsch C, Schmutzhard E, Neumann M, Putensen C, Hackl JM \&Koller W. The secretion of human growth hormone stimulated by human growth hormone releasing factor following severe craniocerebral trauma. Intensive Care Medicine 199016 163-166.

41. Della Corte F, Mancini A, Valle D, Gallizzi F, Carducci F, Mignani V \& De Mannis L. Provocative hypothalamo-pituitary axis tests in severe head injury: correlation with severity and prognosis. Critical Care Medicine1998 26 1419-1426.

42. Chiolero R, Lemarchand T, Schutz Y, de Tribolet N, Felber JP, Freeman J \& Jequier E. Plasma pituitary hormone levels in severe trauma with or without head injury. Journal of Trauma 198828 1368-1374.

43. Bondanelli M, Ambrosio MR, Margutti A, Boldrini P, Basaglia N, Franceschetti P, Zatelli MC \& degli Uberti EC. Evidence for integrity of the growth hormone/insulin-like growth factor-1 axis in patients with severe head trauma during rehabilitation. Metabolism 200251 1363-1369.

44. Ceballos R. Pituitary changes in head trauma (Nalysis of 102 consecutive cases of head injury). Alabama Journal of Medical Sciences 19663 185-198.

45. Kornblum RN \& Fisher RS. Pituitary lesions in craniocerebralinjuries. Archives of Pathology 196988 242-248.

46. Pierucci G, Gherson G \& Tavani M. Pituitary changes -especially necrotic-following craniocerebral injuries. Pathologica 197163 71-88.

47. Crompton MR. Hypothalamic lesions following closed head injury. Brain1971 94 165-172. 
48. Mulligan K \& Schambelan M. Anabolic treatment with GH, IGF-I, or anabolic steroids in patients with HIV-associated wasting. International Journal of Cardiology 200285 151-159.

49. Botfield C, Ross RJ \& Hinds CJ. The role of IGFs in catabolism. Baillieres Clinical Endocrinology and Metabolism 1997 11679-697.

50. Van der Lely AJ. Justified and unjustified use of growth hormone. Postgraduate Medical Journal 200480 577-580.

51. Kissmeyer-Nielsen P, Jensen MB \& Laurberg S. Perioperative growth hormone treatment and functional outcome after major abdominal surgery: a randomized, double-blind, controlled study. Annals of Surgery1999 229 298-302.

52. Takala J, Ruokonen E, Webster NR, Nielsen MS, Zandstra DF, Vundelinckx G \& Hinds CJ. Increased mortality associated with growth hormone treatment in critically ill adults. New England Journal of Medicine 1999341 785-791.

53. Growth Hormone Research Society, Consensus guidelines for the diagnosis and treatment of adults with growth hormone deficiency: summary statement of the Growth Hormone Research Society Workshop on Adult Growth Hormone Deficiency. Journal of Clinical Endocrinology and Metabolism 199883 379-381.

54. Cummings DE \& Merriam GR. Growth hormone therapy in adults. Annual Review of Medicine 200354 513-533.

55. Scheepens A, Sirimanne ES, Breier BH, Clark RG, Gluckman PD \& Williams CE. Growth hormone as a neuronal rescue factor during recovery from CNS injury. Neuroscience 2001104 677-687.

56. Scheepens A, Williams CE, Breier BH, Guan J \& Gluckman PD. A role for the somatotropic axis in neural development, injury and disease. Journal of Pediatric Endocrinology and Metabolism 2000; 13: (Suppl 6) 1483-1491.

\section{AUTHORS:}

1. Vinayak Raje

2. Sangeeta Biradar

3. Mahesh Reddy

4. Madhavendra Kabra

5. Shruthi Panicker

\section{PARTICULARS OF CONTRIBUTORS:}

1. Professor, Department of Neurosurgery, KIMS, Karad.

2. Resident, Department of General Surgery, KIMS, Karad.

3. Resident, Department of General Surgery, KIMS, Karad.

FINANCIAL OR OTHER COMPETING INTERESTS: None
4. Resident Department of General Surgery, KIMS, Karad.

5. Resident, Department of General Surgery, KIMS, Karad.

\section{NAME ADDRESS EMAIL ID OF THE CORRESPONDING AUTHOR:}

Dr. Sangeeta Biradar,

Room No. 34, I. H. R,

P. G. Hostel,

Malakapur-415110, karad.

E-mail: arukadam411@gmail.com

Date of Submission: 25/04/2015.

Date of Peer Review: 26/04/2015.

Date of Acceptance: 22/05/2015.

Date of Publishing: 28/05/2015. 